\title{
Photo-controlled release of zinc metal ions by spiropyran receptors anchored to single-walled carbon nanotubes $\dagger$
}

\author{
Elisa Del Canto, Manuel Natali, Dania Movia and Silvia Giordani* \\ Received 27th January 2012, Accepted 6th March 2012 \\ DOI: $10.1039 / \mathrm{c} 2 \mathrm{cp} 40275 \mathrm{k}$
}

Light controllable release of antinflammatory zinc ions by a smart multifunctional material composed of spiropyrans and single walled carbon nanotubes (SWNTs) is demonstrated. The exploitation of a number of complementary characterization techniques allows the investigation of both composition and performance of the multifunctional SP/SWNT nanomaterial developed. Moreover, its suitability for potential applications in bio-systems is suggested by the effective removal of the metal catalyst and the introduction of biocompatible linkers into the SP/SWNT material. The realization of potential photo controllable SP/SWNTs based drug delivery systems (DDSs) is envisaged, where nanotubes act as intracellular carriers of light modulated receptors for bioactive agents.

\section{Introduction}

Single walled carbon nanotubes (SWNTs) have emerged as efficient intracellular vectors of bioactive payloads for alternative drug delivery and cancer therapy applications. ${ }^{1-9}$ The vast number of covalent, non-covalent or encapsulation approaches reported so far opened the way for the design and the realization of new and more complex SWNT-based drug delivery systems (DDSs). Subsequent to the translocation of such nanosized systems through the phospholipid membrane, the therapeutic effect has shown to be initialized by the release of active drugs following enzymatic cleavage of chemical bonds, ${ }^{10}$ opening of the capped SWNTs hollow chambers by IR or NIR irradiation, ${ }^{11}$ or change in the $\mathrm{pH}$ of the environment. ${ }^{12}$

To date, a number of spiropyran (SP) derivatives have been investigated as receptors and sensors for the recognition and quantification of biomolecules and ions, showing the capability

School of Chemistry/Centre for Research on Adaptive Nanostructures and Nanodevices (CRANN), University of Dublin, Trinity College,

Dublin 2, Ireland.E-mail: giordans@tcd.ie

$\dagger$ Electronic supplementary information (ESI) available: Additional schemes and figures: UV-Vis absorption profiles of functionalized SWNTs used to determine the SP loading; TGA and first derivative traces of all the SWNTs samples; non-baseline corrected ATR/FT-IR spectra of all the nanotube samples; absorption spectra of SP (3) showing its photo interconversion into the ME open form; UV-Vis absorption spectra of raw SWNTs, o-SWNTs and functionalized SWNTs following UV illumination and storage in the dark; emission profiles of PEG reacted SWNTs before and after removal of the Boc protecting group recorded after UV illumination and storage in the dark; comparison of emission profiles of f-SWNTs and SP (2) after UV illumination; emission spectra of o-SWNTs, Tour reacted SWNTs and f-SWNTs before and after the addition of $\mathrm{Zn}\left(\mathrm{ClO}_{4}\right)_{2}$, and o-SWNTs before and after irradiation with Vis light. See DOI: 10.1039/ c2cp $40275 \mathrm{k}$ of complexing metal cations that can ultimately favour the selective ligation of biologically important anions and amino acids. ${ }^{13-15}$ On the other hand, the exploitation of such supramolecular complexes is still in its early stage, as the number of bioactive organic molecules that can potentially interact with them is certainly vast. To the best of our knowledge, SP derivatives have not been used in medicinal chemistry so far. In our group we recently reported the spiropyrans' behaviour as photoregenerable receptors for $\mathrm{Zn}^{2+}$ ions ${ }^{16,17}$ and that strong toxic effects are unlikely to result in vitro from continuous exposure to such molecules at micromolar concentrations. ${ }^{18}$ The essentiality of zinc for humans was discovered almost 50 years ago, but its function as an antinflammatory agent and an adjuvant in cancer prevention has been reported only more recently. ${ }^{19}$ Chronic inflammation has been tightly connected to the development of many forms of cancer, and the linkage between the two conditions is now part of an accepted paradigm of carcinogenesis. ${ }^{20-24} \mathrm{As}$ a consequence, the control of the inflammatory response to tissue damage has become undoubtedly a key factor in cancer treatment and prevention.

In light of our recent study showing the first example of light modulated continuous on-off switching of a SP-SWNT material in solution, ${ }^{25}$ in the present paper we report an investigation on the light controllable uptake and release of zinc ions by a SP receptor anchored to the SWNT scaffolds, thus envisaging appealing applications as photoresponsive DDS.

A good DDS candidate requires to (1) be biocompatible, ${ }^{26}$ (2) have good pharmacokinetic properties (ADME) and to (3) easily release the conjugated bioactive molecule when adequately stimulated. To address the first two requirements, the DDS proposed here will be composed of catalyst free SWNTs covalently modified by Tour reaction on their sidewalls, and subsequently chemically enriched with PEGylated linkers that have demonstrated 
to improve the nanomaterial water dispersibility and, as a consequence, to decrease its immunogenicity and to promote its clearance through the urinary excretion route. ${ }^{5,8,27-32}$ The light responsiveness of the designed SP-based delivery system will provide a flexible control of the pharmaceutically active ions, thus meeting the third requisite.

We believe that the findings reported in this work will open the way towards the design of novel smart DDSs based on light responsive covalently modified SWNTs composites.

\section{Experimental}

\subsection{General methods}

TGA analyses were performed on a PerkinElmer Thermogravimetric Analyzer Pyris 1 TGA. The method used for performing TGA measurements both in air and nitrogen is as follows: 5 minute isothermal step at $30{ }^{\circ} \mathrm{C}$ (to equilibrate the sample); heat from $30{ }^{\circ} \mathrm{C}$ to $100{ }^{\circ} \mathrm{C}$ at a rate of $10{ }^{\circ} \mathrm{C} \mathrm{min}{ }^{-1}$; 20 minute isothermal step at $100{ }^{\circ} \mathrm{C}$ (to ensure evaporation of the solvents); heat from $100{ }^{\circ} \mathrm{C}$ to $900{ }^{\circ} \mathrm{C}$ at a rate of $10{ }^{\circ} \mathrm{C} \mathrm{min}{ }^{-1}$.

FT-IR spectra were measured in the solid state on a PerkinElmer FT-IR Spectrometer Spectrum 100 with a universal ATR sampling accessory (diamond/ZnSe crystal). The spectra were recorded at 256 scans with a $4 \mathrm{~cm}^{-1}$ resolution.

Micro-Raman scattering measurements were carried out at room temperature in the backscattering geometry using a RENISHAW 1000 micro-Raman system equipped with a CCD camera and a Leica microscope. A 1800 lines $\mathrm{mm}^{-1}$ grating was used for all measurements, providing a spectral resolution of $\sim 1 \mathrm{~cm}^{-1}$. As an excitation source the $\mathrm{He}-\mathrm{Ne}$ laser with $633 \mathrm{~nm}$ excitation with variable powers was used. Measurements were taken with 20 seconds of exposure time and 4 accumulations. The laser spot was focused on the sample surface using a $50 \times$ objective with short-focus working distance. Raman spectra were collected on numerous spots on the sample and recorded with a Peltier cooled CCD camera. Only one spectrum was collected per spot. Frequency shifts were calibrated by a $\mathrm{Si}$ reference. The intensity ratio $I_{\mathrm{D}} / I_{\mathrm{G}}$ was obtained by taking the peak intensities after baseline corrections. The data were collected and analyzed with Renishaw Wire and GRAMS software.

The UV-Vis and the UV-Vis-NIR absorption spectra were recorded on a Perkin Elmer UV/Vis Spectrometer Lambda 35 and a Perkin Elmer UV-Vis-NIR Spectrometer Lambda 1050 respectively. All the data were recorded after 1 cycle, with an interval of $1 \mathrm{~nm}$, a slit width of $2 \mathrm{~nm}$ and a scan speed of $240 \mathrm{~nm} \mathrm{~min}^{-1}$. The nanotube samples were dispersed in HPLC grade solvents by sonication (tip and/or bath), centrifuged for a minimum time of $90 \mathrm{~min}$ at $4000 \mathrm{rpm}$ and the absorption spectra were recorded on the supernatant of initial SWNT concentration of $0.1 \mathrm{mg} \mathrm{mL}^{-1}$, except as otherwise stated.

Samples were illuminated by using a portable UVP ultraviolet lamp equipped with a combination of shortwave $(254 \mathrm{~nm}) /$ longwave $(365 \mathrm{~nm})$ and a Schott KL 1500 LCD Visible lamp $(560-900 \mathrm{~nm})$.

Emission spectra were taken in a HORIBA Jobin Yvon Fluorolog-3 Spectrofluorometer equipped with a 450 xenon CV lamp after 1 cycle, with a slit width of $10 \mathrm{~nm}$ and integration time $0.1 \mathrm{~s}$. The nanotube samples were dispersed in HPLC grade solvents by sonication (tip and/or bath), centrifuged for a minimum time of $90 \mathrm{~min}$ at $4000 \mathrm{rpm}$ and the emission spectra were recorded on the supernatant of initial SWNT concentration of $0.1 \mathrm{mg} \mathrm{mL}^{-1}$ or $0.01 \mathrm{mg} \mathrm{mL}^{-1}$, except as otherwise stated.

AFM topographic images were collected in semi-contact mode with an NT-MDT inverted configuration system. Silicon tips with reflectance gold coated on the back, tip apex radius $10 \mathrm{~nm}$, force constant $2 \mathrm{~N} \mathrm{~m}^{-1}$ and frequency $170 \mathrm{kHz}$ were used. The data were collected and analyzed with NT-MDT Nova software. Samples were prepared for analysis by dispersing the nanotubes in high purity DMF by sonication and spin coating on mica substrates (results in Chapter 2) or by dispersing the nanotubes in high purity DMF by sonication, spray coated onto freshly cleaved mica substrates and dried overnight in an oven at $90{ }^{\circ} \mathrm{C}$.

For High Resolution Transmission Electron Microscopy (HR-TEM) SWNT powders were dispersed in high purity DMF $\left([\mathrm{SWNTs}]_{i}=0.1 \mathrm{mg} \mathrm{mL}{ }^{-1}\right)$ by sonic tip and sonic bath. The samples were prepared by dropping an aliquot $(10 \mu \mathrm{L} \mathrm{ca}$.) of the dispersions on 200 mesh $\mathrm{Cu}$ holey carbon grids and incubating for some minutes. The grids were then drained, dried for 1 day at $37{ }^{\circ} \mathrm{C}$ and visualized under Jeol 2100 operating at $200 \mathrm{kV}$ with a Lanthanum Hexaborise emission source.

The standard procedure used in all the Kaiser tests was performed as follows: exact weight of $1.0 \mathrm{mg}$ of f-SWNTs; addition of $75 \mu \mathrm{l}$ of solution 1 ( $80 \mathrm{~g}$ of phenol in $20 \mathrm{~mL}$ of EtOH); addition of $100 \mu \mathrm{l}$ of solution 2 (2 mL of KCN $1 \mathrm{mM}$ in $98 \mathrm{~mL}$ of pyridine); addition of $75 \mu \mathrm{l}$ of solution 3 ( $1 \mathrm{~g}$ of ninhydrin in $20 \mathrm{~mL}$ of EtOH); solution heating at $100{ }^{\circ} \mathrm{C}$ for 7 minutes under vigorous stirring; dilution with $\mathrm{EtOH}$ until the volume of $5 \mathrm{~mL}$; sonication for 7 minutes.

In order to quantify the $\mu \mathrm{mol}$ of amino groups per gram the following equation is applied:

$\mu \mathrm{mol} \mathrm{g}{ }^{-1}=\frac{[\text { abs. sample }- \text { abs. blank }] \times \text { diluition }(\mathrm{ml}) \times 10^{6}}{\text { extinction coeff } . \times \text { sample weight }(\mathrm{mg})}$

The extinction coefficient is also known as molar absorptivity and represents how efficiently a chemical species absorbs light at a given wavelength. For CNTs this coefficient has a value of $15000 \mathrm{M}^{-1} \mathrm{~cm}^{-1}$. A single Kaiser test was conducted for each of the prepared samples.

\subsection{Experimental procedures}

2.2.1. Materials. SWNTs were purchased from Unidym ${ }^{\circledR}$, Inc. (Lot no. R0513). Reagents and solvents were purchased as reagent-grade from Fisher Scientific Ireland Ltd, or SigmaAldrich Ireland and used without further purification.

2.2.2. Preparation of purified/oxidized o-SWNTs. The o-SWNTs were synthesized according to the literature procedure previously reported. ${ }^{33}$

2.2.3. Preparation of benzoic acid functionalized SWNTs. $60 \mathrm{mg}$ of o-SWNTs were dispersed in NMP $(250 \mathrm{~mL})$ by sonication at full power for $30 \mathrm{~min}$. Following addition 
of $p$-aminobenzoic acid ( $1.37 \mathrm{~g}, 0.01$ moles, 2 equiv.) the mixture was sonicated at full power for additional $15 \mathrm{~min}$. Isoamylnitrite ( $2 \mathrm{~mL}, 0.015$ moles, 3 equiv.) was added and the mixture was stirred at $70{ }^{\circ} \mathrm{C}$ overnight under a nitrogen atmosphere. After cooling down to room temperature, the nanotubes were filtered through a $0.2 \mu \mathrm{m}$ Millipore Fluoropore filter and washed with NMP $(300 \mathrm{~mL})$. The latter procedure was repeated three times. The nanotube mixture was finally filtered through a $0.2 \mu \mathrm{m}$ Millipore Fluoropore filter and rinsed with NMP (300 mL) and DMF (400 mL). The residue was collected, dispersed in DMF (100 mL), sonicated at full power for $20 \mathrm{~min}$ and filtered on a new Millipore filter. The residue was finally washed with $\mathrm{MeOH}(500 \mathrm{~mL})$ and dried under vacuum to afford benzoic acid functionalized SWNTs $(75.5 \mathrm{mg})$. FT-IR $\nu\left(\mathrm{cm}^{-1}\right)$ : 3305 (O-H), 2958, 2920, $2851(\mathrm{C}-\mathrm{H}), 1699(\mathrm{C}=\mathrm{O}), 1572,1539$ $(\mathrm{C}=\mathrm{C}), 1378$ (O-H), 1401, 1314 (C-C), 1205 (C-O-C), 1151 (C-O).

2.2.4. Preparation of PEG functionalized SWNTs. $40 \mathrm{mg}$ of benzoic acid functionalized SWNTs were dispersed in DMF $(100 \mathrm{~mL})$ by sonication at full power for $90 \mathrm{~min}$. After cooling down in an ice bath, the nanotube solution was added of 1-ethyl-3-(3 dimethylaminopropyl)carbodiimide hydrochloride (EDC.HCl) (49 mg in $10 \mathrm{~mL}$ of DMF) and sonicated for additional $45 \mathrm{~min}$ in a sonic bath. The mixture was subsequently stirred in an ice bath for $30 \mathrm{~min}$ in order to activate the $\mathrm{COOH}$ groups. $\mathrm{N}$-Hydroxysuccinimide (NHS) $(32 \mathrm{mg}$ in $10 \mathrm{~mL}$ of DMF) was added and the dispersion was sonicated for another $30 \mathrm{~min}$ and cooled down in an ice bath. $89 \mathrm{mg}$ of tert-butyl 3-(2-(2-(3-aminopropoxy)ethoxy)ethoxy)propylcarbamate (4) were dissolved in DMF $(10 \mathrm{~mL})$ and added to the mixture in small excess. After the addition of $N, N$-diisopropylethylamine (DIPEA) $(100 \mu \mathrm{L})$ the nanotube mixture was stirred at room temperature for 4 and half days. The functionalized nanotubes were collected as a black precipitate and filtered through a Millipore system $(0.2 \mu \mathrm{m}$ Fluoropore FG filter). The solid was washed with DMF $(600 \mathrm{~mL})$ and was then re-dispersed in DMF $(100 \mathrm{~mL})$ by sonication in a sonic bath at full power for $20 \mathrm{~min}$. The material was filtered on a new Millipore FG filter and washed with DMF (500 mL) and $\mathrm{MeOH}(500 \mathrm{~mL})$. The residue was dried under vacuum to afford PEG functionalized SWNTs (42.4 mg). FT-IR $\nu\left(\mathrm{cm}^{-1}\right): 3287(\mathrm{~N}-\mathrm{H}), 2916,2849$ (C-H), 1688, $1642(\mathrm{C}=\mathrm{O}), 1587,1530,1443(\mathrm{C}=\mathrm{C}), 1364(\mathrm{C}-\mathrm{O})$, 1213, 1158 (C-O-C).

2.2.5. Preparation of spiropyran f-SWNTs. A $37.5 \mathrm{mg}$ quantity PEG functionalized SWNTs were dispersed in DMF $(400 \mathrm{~mL})$ and sonicated in a sonic bath at full power for $120 \mathrm{~min}$. A $3 \mathrm{~mL}$ aliquot of trifluoroacetic acid (TFA) was added and the mixture was stirred at room temperature for $21 \mathrm{~h}$. The black product was filtered through a Millipore system (on a $0.2 \mu \mathrm{m}$ fluoropore FG filter), washed with DMF $(150 \mathrm{~mL})$ and quenched with triethylamine $(3 \mathrm{~mL})$. The residue on the filter was collected, re-dispersed in DMF $(100 \mathrm{~mL})$ and sonicated in a sonic bath for $10 \mathrm{~min}$. The dispersion was filtered again through a new $0.2 \mu \mathrm{m}$ Millipore Fluoropore filter. The filtered off solution was brown and, to ensure that no nanotubes passed through the filter, the filtering procedure was repeated 3 times. This still resulted in a brown filtrate due to the high quantity of carbonaceous material removed from the sample. The functionalized nanotubes left on the filter were washed with DMF $(150 \mathrm{~mL})$, toluene $(50 \mathrm{~mL})$, $\mathrm{Et}_{2} \mathrm{O}(50 \mathrm{~mL}), \mathrm{CH}_{2} \mathrm{Cl}_{2}(50 \mathrm{~mL})$ and $\mathrm{MeOH}(250 \mathrm{~mL})$. The sample was dried under reduced pressure to afford $33.7 \mathrm{mg}$ of Boc deprotected SWNTs. FT-IR $\nu\left(\mathrm{cm}^{-1}\right)$ : 3332, $3281(\mathrm{~N}-\mathrm{H})$, 2905, 2864 (C-H), 1687, $1648(\mathrm{C}=\mathrm{O})$, 1590, 1526, 1498, 1446 $(\mathrm{C}=\mathrm{C}), 1364$ (C-O), 1204, 1158 (C-O-C). $10 \mathrm{mg}$ of the spiropyran $(\mathrm{SP}, 2)$ were dispersed in dry DMF $(20 \mathrm{~mL})$, added of $\mathrm{EDC} \cdot \mathrm{HCl}(4.8 \mathrm{mg})$ and stirred in an ice bath for $10 \mathrm{~min}$ under a $\mathrm{N}_{2}$ atmosphere, until the activated ester was formed (motored by TLC in hexane/EtOAc 2:8). NHS (5 mg) and pyridine $(\sim 1 \mathrm{~mL})$ were added and the mixture was stirred in an ice bath for $1 \mathrm{~h}$ under a $\mathrm{N}_{2}$ atmosphere. $30 \mathrm{mg}$ of previously obtained Boc deprotected SWNTs were sonicated in dry DMF $(100 \mathrm{~mL})$ for $5 \mathrm{~min}$, and were added to the activated spiropyran solution. The spiropyran-nanotube mixture was stirred at room temperature for 3 days under a nitrogen atmosphere. The product was collected as a black precipitate, was filtered through a Millipore system (on a $0.2 \mu \mathrm{m}$ fluoropore FG filter) and washed with DMF $(300 \mathrm{~mL})$. The residue was collected, re-dispersed in DMF (100 $\mathrm{mL})$ and sonicated for $2 \mathrm{~min}$. The SWNTs were refiltered through a Millipore system (on a new $0.2 \mu \mathrm{m}$ fluoropore FG filter) and washed with DMF $(150 \mathrm{~mL})$, toluene $(100 \mathrm{~mL}), \mathrm{Et}_{2} \mathrm{O}(100 \mathrm{~mL}), \mathrm{CH}_{2} \mathrm{Cl}_{2}(300 \mathrm{~mL})$ and $\mathrm{MeOH}$ $(200 \mathrm{~mL})$ to completely remove any unreacted products. The black solid was dried under reduced pressure to afford $29 \mathrm{mg}$ of SP f-SWNT. FT-IR $\nu\left(\mathrm{cm}^{-1}\right):$ 3285, $3120(\mathrm{~N}-\mathrm{H}), 2917,2866$ $(\mathrm{C}-\mathrm{H}), 1646(\mathrm{C}=\mathrm{O}), 1553,1367\left(\mathrm{NO}_{2}\right), 1565,1447(\mathrm{C}=\mathrm{C})$, 1311, 1225, 1150 (C-O-C).

2.2.6. Preparation of SP (2). The spiropyran 4-(8-methoxy3', $3^{\prime}$-dimethyl-6-nitrospiro[chromene-2,2'-indolin]-1'-yl)butanoic acid was synthesized according to the literature procedure previously reported. ${ }^{16}$

\subsection{Bio experiments}

2.3.1. Dispersion of SP f-SWNTs. Dry powder f-SWNTs were weighted and added to sterile DMSO at a concentration of $0.1 \mathrm{mg} \mathrm{mL}^{-1}$ (stock solution). Stock solution was sonicated (sonic bath, 4 h). 9 mL of RPMI 1640 cell media (supplemented with $2 \mathrm{mM}$ L-glutamine, 10\% foetal bovine serum (FBS) and $10 \mathrm{mg} \mathrm{mL}^{-1}$ penicillin- streptomycin) was mixed with $1 \mathrm{~mL}$ of stock solution, thus obtaining a final SWNTs concentration of $10 \mu \mathrm{g} \mathrm{mL}^{-1}$.

2.3.2. Cell culture. Human monocytic leukemia (THP-1) cells were obtained from the American Tissue Culture Collection (ATCC). Briefly, THP-1 cells were cultured in suspension in modified RPMI 1640 media (supplemented with $2 \mathrm{mM}$ L-glutamine, $10 \%$ foetal bovine serum (FBS) and $10 \mathrm{mg} \mathrm{mL}^{-1}$ penicillin- streptomycin) and incubated at $37{ }^{\circ} \mathrm{C}$ and $5 \% \mathrm{CO}_{2}$. At $60 \%$ confluence, cells were diluted in modified RPMI 1640 media at concentrations appropriate for the experimental procedure. The passage number was restricted between five and fifteen.

2.3.3. Incubation with f-SWNTs dispersions. THP-1 cells were seeded on glass cover slips in 24-well plates and activated with phorbol-12-myristate-13-acetate (PMA) (Sigma-Aldrich, USA) for $72 \mathrm{~h}$ to induce differentiation into adherent macrophages and stop their natural proliferation. After removing the cell media, 
adherent THP-1 cells were exposed to SP f-SWNTs (3) dispersions in supplemented RPM1 1640 cell media. After $24 \mathrm{~h}$ incubation cells were carefully recovered from the wells and placed on a HistoBond microscope slide (RA Lamb, UK). Samples were then fixed with $90 \%$ ethanol and subsequently rinsed with saline. F-actin was labeled by adding $2 \mathrm{U} \mathrm{mL}^{-1}$ of the Phalloidin-Alexa 546 conjugate (Invitrogen, UK). The slides were incubated at room temperature in the dark for $30 \mathrm{~min}$, rinsed with saline and mounted in Vectashield (Vector, UK) prior to epifluorescence microscopy analysis. Specimens were examined with an Olympus BX51M reflection epi-fluorescence microscope equipped with standard PC and the Cell-D image acquisition/processing software (Soft Imaging System, SIS, GmbH).

\section{Results and discussion}

\subsection{Purification and functionalization of SWNTs}

Commercially available raw HiPco SWNTs $\left(\right.$ Unidym $\left.^{\circledR}\right)$ were purified and oxidized by successive treatments with nitric acid, sodium hydroxide and hydrogen peroxide (Scheme 1), by a recently reported protocol optimized in our lab. ${ }^{33}$ The latter was specifically chosen as it found to be effective in the removal of both unwanted metal catalyst and carbonaceous material from the sample without affecting the tubes' integrity. The purified material (o-SWNTs) was subsequently treated with in situ generated 4-carboxybenzenediazonium salts to

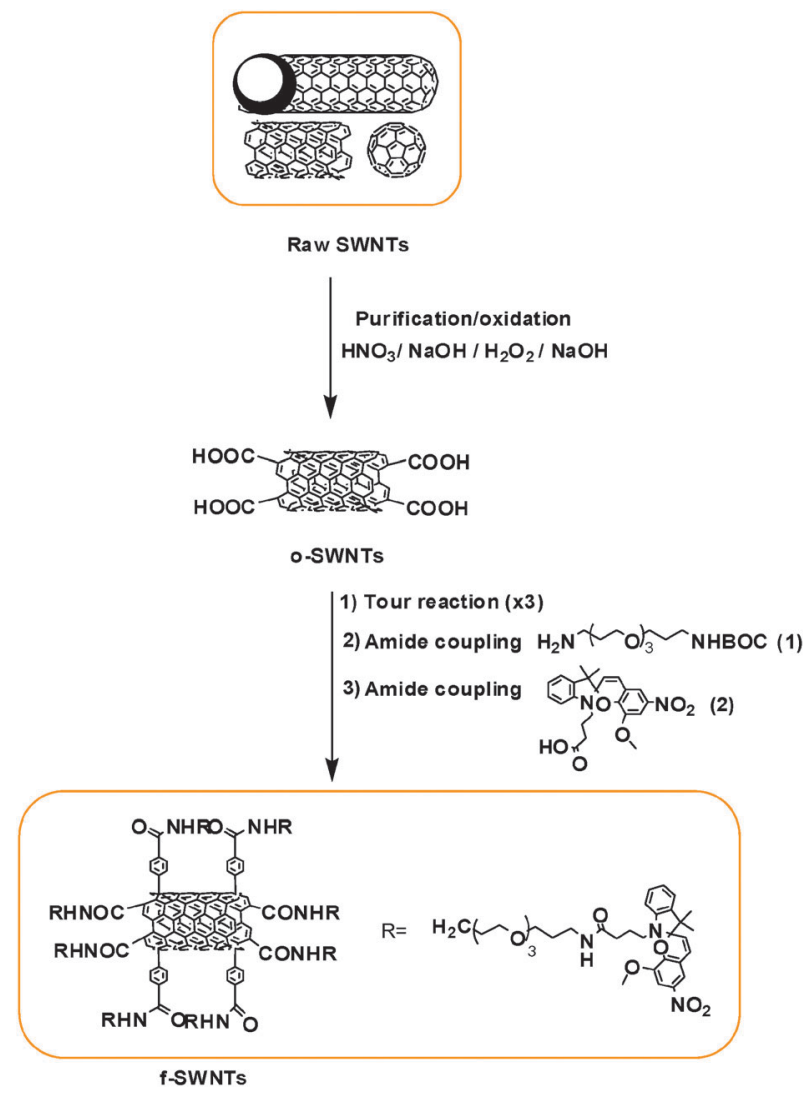

Scheme 1 Purification, sidewall covalent functionalization of SWNTs with benzoic acid, and amide coupling with the PEG linker and spiropyran derivative.

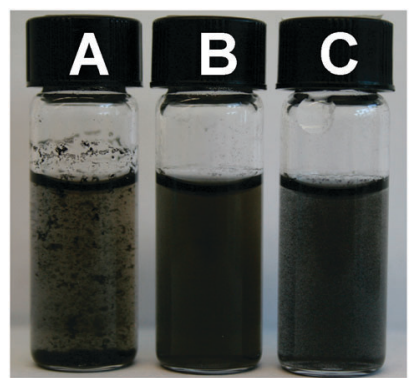

Fig. 1 Pictures of SWNTs dispersions after (A) purification and functionalization with (B) benzoic acid and (C) SP derivative. [SWNTs] $=0.1 \mathrm{mg} \mathrm{mL}^{-1}$ distilled $\mathrm{H}_{2} \mathrm{O}$, sonication time $30 \mathrm{~min}$ at minimum power. Pictures taken $1 \mathrm{~h}$ after sonication ceased.

functionalize the nanotube sidewalls. To ensure a high degree of benzoic acid functionalities and a good dispersibility in solvents, the "Tour reaction" was carried out for three consecutive times. ${ }^{34}$ To further improve the dispersibility of SWNTs in aqueous solvents and to create at the same time a more biocompatible material, a Boc-protected PEGylated linker (1) was chosen as an ideal hydrophilic spacer to be interposed between the nanotube scaffold and the photoactive functionality. Compound (1) was coupled to Tour reacted SWNTs, following activation of the benzoic acid groups to the corresponding ester using NHS and EDC.HCl. The Boc protecting group was subsequently removed by trifluoroacetic acid treatment, and the nanotubes bearing free amino groups were reacted with the activated ester of the spiropyran derivative (2) synthesized in our lab, ${ }^{16,35}$ to afford SP functionalized nanotubes f-SWNTs.

Fig. 1 clearly illustrates the improved solubility of SWNTs in aqueous solution after covalent sidewall modification (Fig. 1B and C). The solubility of a nanomaterial in water is of crucial importance if its envisaged applications involve bio-environments. As a consequence the demonstrated water solubility of f-SWNTs is paramount as potential DDSs based on such photoactive modular systems are here investigated.

The amount of functionalities introduced onto the nanotube sidewalls was investigated by a Kaiser test. ${ }^{36,37}$ The difference in free primary amino groups before and after coupling reaction of the nanotubes with SP was calculated by measuring their absorbance at $570 \mathrm{~nm}$ relative to a blank solution (Fig. S1 in the ESI $\dagger$ ). The SP loading was calculated as $\sim 106 \mu \mathrm{g} \mathrm{mg}^{-1}$ SWNTs. If this value is compared to the one obtained for SWNTs covalently coupled to SP via the defect site approach previously reported ${ }^{25}$ the enrichment with a larger number of functional groups is evident in the present case, as expected and aimed.

\subsection{Characterization of purified and functionalized SWNTs}

Thermogravimetric analysis and TEM images. TGAs were recorded in an oxygen atmosphere to assess the successful purification of raw SWNTs after treatment with $\mathrm{HNO}_{3}$, $\mathrm{NaOH}$ and $\mathrm{H}_{2} \mathrm{O}_{2}$. The residual ash content at $900{ }^{\circ} \mathrm{C}$, which dropped from $48 \%$ to $8 \%$, is an indication of the efficient removal of the metal catalyst, as evident from TGA traces in Fig. 2. The $8 \%$ value registered after combustion of o-SWNTs can be more likely assigned to the presence of small quantities 

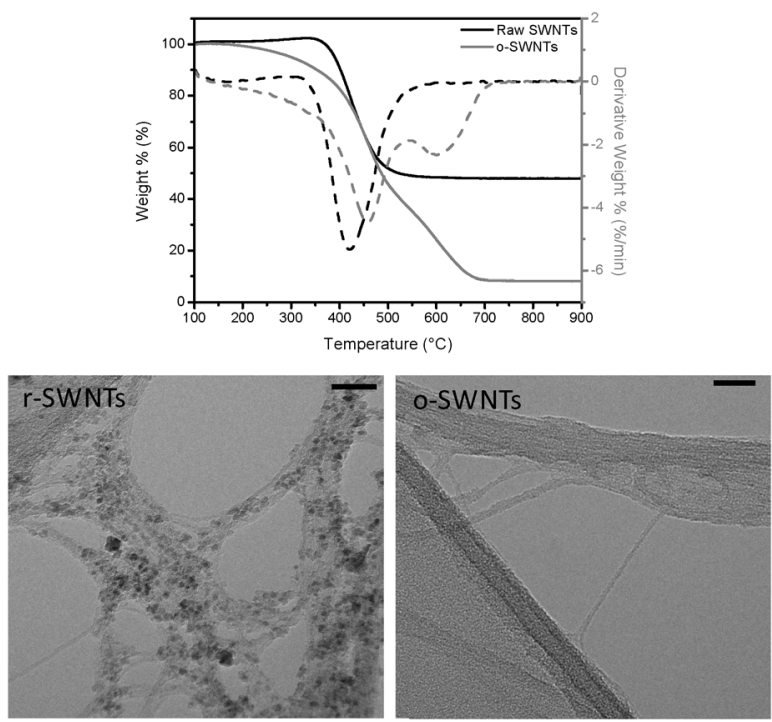

Fig. 2 (Top) TGA traces (solid lines) evidencing the effective purification of raw SWNTs after treatment with $\mathrm{HNO}_{3}, \mathrm{NaOH}$ and $\mathrm{H}_{2} \mathrm{O}_{2}$. TGA and first derivative traces (dotted lines) of raw SWNTs and purified (o-SWNTs) nanotubes run in an air atmosphere. (Bottom) HR-TEM images of raw (left) and purified (right) SWNTs on 200 mesh $\mathrm{Cu}$ holey carbon grids demonstrating the removal of the metal impurities (black particles) after nitric acid purification and treatment with $\mathrm{NaOH}$ and $\mathrm{H}_{2} \mathrm{O}_{2}$. Scale bar: $20 \mathrm{~nm}$.

of residual salt coming from the washing procedure with $\mathrm{NaOH}$. This assumption was confirmed by TEM analysis, where the metal catalyst totally disappeared after the purification protocol, as shown in Fig. 2.

An additional indication of the successful cleaning of the sample from metal particles and carbonaceous impurities was given by the starting decomposition temperature of the SWNTs' graphitic structure. In the presence of impurities, hot spots are usually generated on the SWNTs surface which entail the burning of the material at lower temperatures. ${ }^{38}$ When first derivative traces of r-SWNTs and o-SWNTs were compared (Fig. 2) the increased oxidative stability of the material from 420 to $460{ }^{\circ} \mathrm{C}$ further indicated the effective removal of unwanted impurities after purification and treatment with $\mathrm{NaOH}$ and $\mathrm{H}_{2} \mathrm{O}_{2}$.

To estimate the number of functional groups introduced onto the nanotube surface after chemical modification and, more importantly, to determine as to whether functionalization with SP derivative was achieved, TGA analyses were performed in an inert nitrogen atmosphere for all the samples (full range traces reported in ESI $\dagger$, Fig. S2). As schematized in Table 1, the weight loss $\%$ at $500{ }^{\circ} \mathrm{C}$, which is attributable to the decomposition of organic functionalities, increased considerably going from raw to purified and SP functionalized SWNTs. This is indicative of the different composition of the materials and, as a consequence, of the diverse number of functional groups introduced onto their surface. The decreased number of functional groups per carbon atom calculated for f-SWNTs is attributed to the removal of residual functionalized carbonaceous fragments following exhaustive solvent washings.

The successful introduction of SP molecules into the nanotube material was also confirmed by the temperature difference maxima between raw SWNTs, o-SWNTs and functionalized
Table 1 Weight losses $\%$ at $500{ }^{\circ} \mathrm{C}$ attributed to the decomposition of organic functionalities, estimated number of carbon atoms per organic group and residue percentages after decomposition in a nitrogen atmosphere are reported for raw, purified and functionalized SWNTs

\begin{tabular}{llll}
\hline & \multicolumn{3}{l}{ TGA in nitrogen } \\
\cline { 2 - 4 } Sample & $\begin{array}{l}\text { Weight loss } \% \\
\text { 1 } 500{ }^{\circ} \mathrm{C}\end{array}$ & $\begin{array}{l}\text { 1 functional } \\
\text { group every }\end{array}$ & $\begin{array}{l}\text { Residue } \% 900{ }^{\circ} \mathrm{C} \\
\text { @ } 90\end{array}$ \\
\hline Raw SWNTs & 3 & - & 70 \\
o-SWNTs & 12 & - & 69 \\
Tour reacted SWNTs & 28 & $26 \mathrm{C}$ & 59 \\
PEG reacted SWNTs & 35 & $50 \mathrm{C}$ & 53 \\
TFA treated PEG & 30 & $63 \mathrm{C}$ & 64 \\
reacted SWNTs & 33 & $124 \mathrm{C}$ & 53 \\
f-SWNTs & & & \\
\hline
\end{tabular}

SWNTs in the $100-500{ }^{\circ} \mathrm{C}$ range, and the organic loading for f-SWNTs was calculated as 1 group every $124 \mathrm{C}$ atoms (see ESI†, Fig. S3).

3.2.1. Atomic force microscopy analysis. AFM topographic images were recorded for all the samples dispersed in DMF and sprayed on a freshly cleaved mica substrate, with the aim of confirming the cleanliness of the purified material and its effective disentangling after chemical functionalization (Fig. 3). When raw SWNTs and o-SWNTs are compared, the efficient removal of the metal catalyst and impurities is once more confirmed: raw material is composed of a big portion of carbonaceous material and catalytic particles (dots), while following purification only small bundles of clean nanotubes are left. The improved debundling of nanotubes after chemical modification is suggested by the distribution of almost all individual tubes in the functionalized SWNT samples. The chemical protocol here utilized has demonstrated to only slightly affect the tubes' integrity. ${ }^{33}$

3.2.2. FT-IR spectroscopy analysis. The introduction of functional groups onto the nanotube surface was monitored by FT-IR spectroscopy. Characteristic absorption bands assignable to stretching vibrations of specific functional groups are clearly evident from the baseline corrected spectra illustrated in Fig. 4 (non-corrected FT-IR spectra in ESI $\dagger$, Fig. S4).

Following purification absorption stretching bands associated to carbonyl groups $\left(1743 \mathrm{~cm}^{-1}\right)$ and $\mathrm{C}=\mathrm{C}$ bonds of the nanotube structure $\left(1567 \mathrm{~cm}^{-1}\right)$ emerged, thus confirming the introduction of carboxylated functionalities onto the nanotube frame by conversion of defect sites to functionalizable $-\mathrm{COOH}$ groups. ${ }^{33}$ After functionalization of the nanotube sidewalls by Tour reaction, new bands appeared in the region where $\mathrm{O}-\mathrm{H}$ and $\mathrm{C}-\mathrm{O}$ groups absorb (Fig. 4A). The latter besides the increased intensity of both carbonyl and $\mathrm{C}=\mathrm{C}$ signals suggested the effective introduction of benzoic acid groups onto the nanotube surface. Upon comparison of the TFA treated PEG-SWNTs spectrum with that of the Tour functionalized material, additional bands that suggested the successful coupling of the PEG linker to the benzoic acid residue were observed (peak assignments reported in the experimental part). Finally when IR measurements were performed on f-SWNTs the two distinctive nitro absorption 

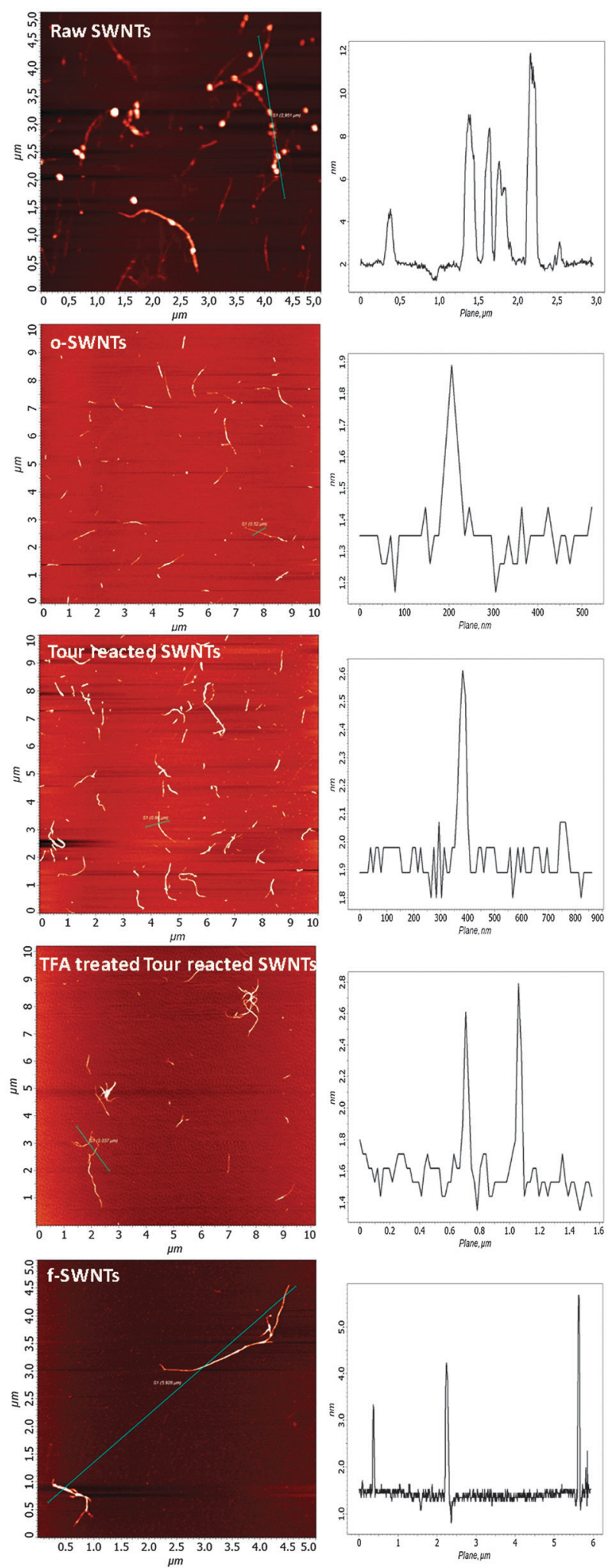

Fig. 3 AFM topographic images of raw SWNTs, o-SWNTs, Tourreacted, PEG-reacted and SP f-SWNTs. Z-slide: raw SWNTs 0-10 nm, o-SWNTs and Tour-reacted SWNTs $0-2.5 \mathrm{~nm}$, TFA treated PEG-reacted SWNTs $0-3.7 \mathrm{~nm}$, f-SWNTs $0-4 \mathrm{~nm}$.

bands at 1553 and $1367 \mathrm{~cm}^{-1}$ appeared (Fig. 4B), confirming the presence of the spiropyran molecule in the nanomaterial.
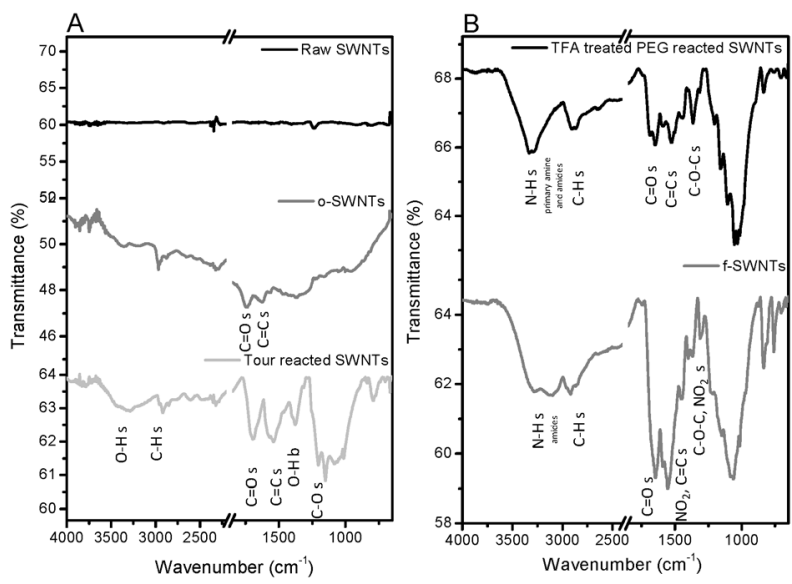

Fig. 4 ATR/FT-IR spectra of (A) raw SWNTs, purified (o-SWNTs) and Tour-reacted SWNTs, (B) TFA treated PEG-reacted SWNTs and f-SWNTs. Spectra have been baseline corrected to improve data visualization.

3.2.3. Raman spectroscopy analysis. Raman spectroscopy was used as a preferential technique to monitor the extent of defects introduction following the chemical processes. The relative intensity of defect (D) and graphitic $(\mathrm{G})$ bands was taken into account, as their ratio $\left(I_{\mathrm{D}} / I_{\mathrm{G}}\right)$ is commonly calculated to investigate the degree of covalent functionalization on the nanotube structure. An increased $I_{\mathrm{D}} / I_{\mathrm{G}}$ ratio indicates a perturbation of the graphene sheet symmetry that is ascribable to the insertion of defects/edge planes and, as a consequence, functionalities on the nanotube framework. Fig. 5 depicts Raman spectra of raw, purified and Tour-reacted SWNTs and it reports the $I_{\mathrm{D}} / I_{\mathrm{G}}$ values calculated for all the considered samples. As expected, only slight changes are observed in RBM, 2D- and G- bands following the Tour reaction, while the D-band is strongly affected indicating covalent functionalization.

Following attachment of the PEG chain and coupling to SP, the intensity of the defect sensitive D-band stayed almost unaltered as expected. This is evident when D-, G- and RBM bands are enlarged (Fig. S5 in ESI $\dagger$ ). The sharpening and restored symmetry of the D-band after progressive functional groups enrichment can be explained with the removal of small amounts of residual CCFs by exhaustive washing with solvents. When the RBM region of raw and purified o-SWNTs are compared (Fig. S5B in ESI $\dagger$ ), the destruction of small diameter tubes by nitric acid treatment is confirmed by the disappearance of RBM bands resonant at shift values $>280 \mathrm{~cm}^{-1}$.

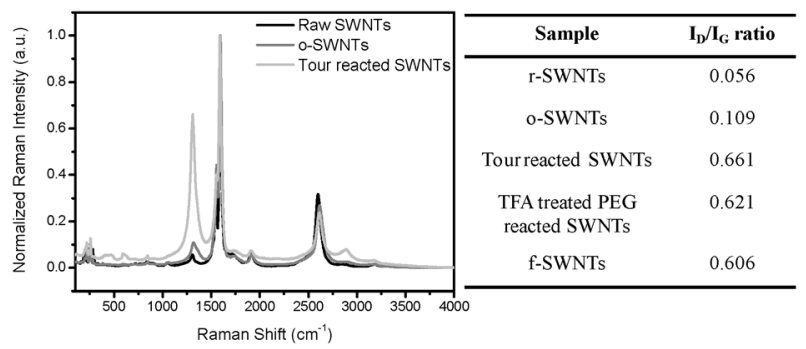

Fig. 5 Raman analyses $\left(\lambda_{\text {exc }}=633 \mathrm{~nm}\right.$ ). (Figure) Raman spectra (normalized on the G-band) of raw, purified and Tour-reacted SWNTs. (Table) $I_{\mathrm{D}} / I_{\mathrm{G}}$ ratio calculations. 


\subsection{On-off switching of SWNTs functionalized with spiropyran molecules}

Before investigating the switching behavior of f-SWNTs, the optical changes induced by UV light irradiation and storage in the dark on the corresponding SP derivative in solution were studied. The reversible interconversion of SP (3) in the ME open isomer was demonstrated by modulation of the absorption band at $593 \mathrm{~nm}$ following irradiation with UV light $(365 \mathrm{~nm})$ for 1 minute. This band, that corresponds to the ME form of the dye, reverted back to the starting value after 3 minutes in the dark (Fig. S6 in ESI $\dagger$ ). The electronic properties of raw, purified and sidewall covalently modified SWNTs were evaluated by UV-Vis absorption spectra of DMF solutions (Fig. 6). Following purification the optical features were retained, while the diazonium treatment resulted in the complete loss of van Hove singularities in agreement with numerous published articles. ${ }^{34,39-46}$ The loss of optical transitions in the absorption spectra of Tour-reacted SWNTs, PEG-reacted and f-SWNTs is indicative of covalent functionalization. In SP f-SWNTs a peak at $416 \mathrm{~nm}$ was detectable, which corresponds to the SP closed isomeric form coupled to the PEG linker. As previously reported, ${ }^{25}$ the absorption maximum of SP was red-shifted if compared to the one of the molecule in solution, as an indication of the SP/SWNT interactions.

The photoresponsive retention of the SP switch when coupled to SWNTs was investigated via both absorption and emission spectroscopies (Fig. 7), and the optical changes that occurred after UV irradiation and storage in the dark were measured. UV irradiation resulted, as expected, in an increased absorbance in the ME isomer region (500-600 nm). The reversion of the band at $585 \mathrm{~nm}$ to the starting value after storage in the dark is demonstrated in Fig. 7A. For improving the visualization of the switching behavior, absorption spectra of f-SWNTs were subtracted from the one recorded after UV illumination and darkness (inset Fig. 7A). The ME absorption maximum

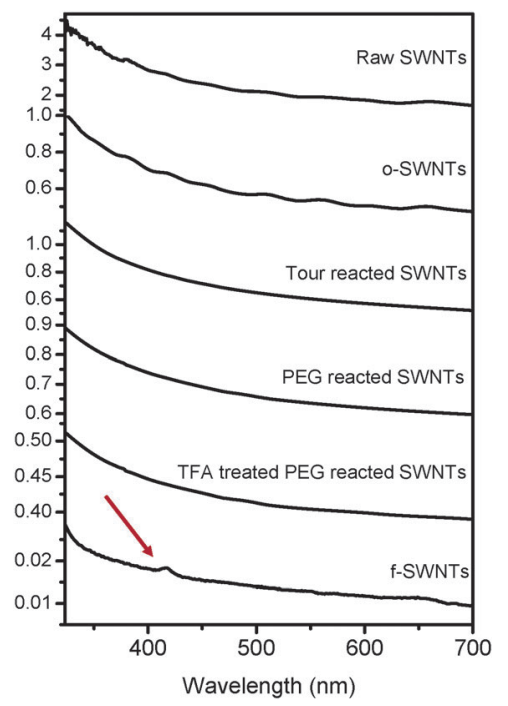

Fig. 6 UV-Vis absorption spectra of raw SWNTs, o-SWNTs and sidewall functionalized SWNTs collected on the supernatant of initial $0.1 \mathrm{mg} \mathrm{mL}^{-1}$ nanotubes in DMF. The arrow indicates the absorption peak ascribable to SP coupled to the nanomaterial. blue-shifted compared to the one of the molecule in solution as an indication of the interaction between the photoactive molecule and the tubes. ${ }^{47}$ Analogous experiments were performed on raw, purified and all the functionalized SWNTs that showed no photoresponsiveness (Fig. S7 in the ESI $\dagger$ ), thus further supporting the enrichment of f-SWNTs with the desired photoactive receptor. It was possible to modulate cyclically and reversibly the switching of the spiro molecule covalently attached to the nanotube material through the PEG linker, and the changes in absorption intensity of the band at $585 \mathrm{~nm}$ are reported in Fig. 7B, where on-off switching cycles are depicted. The photoswitchability of the SP-SWNTs composite was proved also by emission spectroscopy (Fig. 7C). An emission band at $670 \mathrm{~nm}$, which is associated to the ME open form, was clearly detectable after UV irradiation of f-SWNTs dispersed in DMF. This emission peak could be cyclically modulated by UV illumination ( $2 \mathrm{~min}$ ) and storage in the dark (5 min), thus confirming the switchability of the nanotube material. Emission spectra, excited at $\lambda_{\mathrm{exc}}=593 \mathrm{~nm}$, of f-SWNTs before and after UV irradiation, and after storage in the dark are reported in Fig. 7C, while in Fig. 7D the on-off switching cycles are shown.

To ensure that the photoswitchable emission band belonged to the SP molecule, the same experiments were performed on PEG-reacted SWNTs before and after removal of the Boc protecting group. In no cases changes were recorded and the emission profiles are reported in Fig. S8 in the ESI. $\dagger$ The emission behavior of the SP alone was recorded and compared to that of f-SWNTs (Fig. S9 in ESI $\dagger$ ). Bands at a slightly shifted wavelength were observed, which could be ascribable to a change in stabilization of the excited transition state of the molecule in the presence of nanotubes. As a consequence, the interaction between the two constituents of the SP/SWNTs nanodevice synthesized was again confirmed.

\subsection{Uptake and release of zinc metal ions by spiropyran receptors}

The complexation and the release of zinc metal ions by SP (3) in solution were demonstrated to be fully controllable and modulated by using visible light rather than UV light, as pictured in Fig. 8.

However, when the photoactive molecule is anchored to a SWNTs scaffold, the detection of metal ions becomes more challenging because of the intrinsic optical features and of the strong absorption background of SWNTs. The latter might impede the straightforward assignment or even the detection of signals coming from the non-nanotube fraction by absorption spectroscopy. In the present work, the more sensitive emission spectroscopy is used to demonstrate both the chelation and the light modulated release of zinc by the SP f-SWNTs. The f-SWNTs solution was added of $\mathrm{Zn}\left(\mathrm{ClO}_{4}\right)_{2}$, left equilibrated in the dark and the emission spectrum $\left(\lambda_{\mathrm{exc}}=440 \mathrm{~nm}\right)$ was collected. The band recorded at $508 \mathrm{~nm}$ can be attributed to the formation of the ME-Zn complex since its shape and shift values are comparable to that of the ME-Zn free in solution, and as its intensity can be modulated by Vis light (Fig. 9). Sequential conversions between the closed form of the receptor and ME-Zn complex anchored to SWNTs scaffolds were recorded after the addition of the metal followed by light and darkness cycles. 

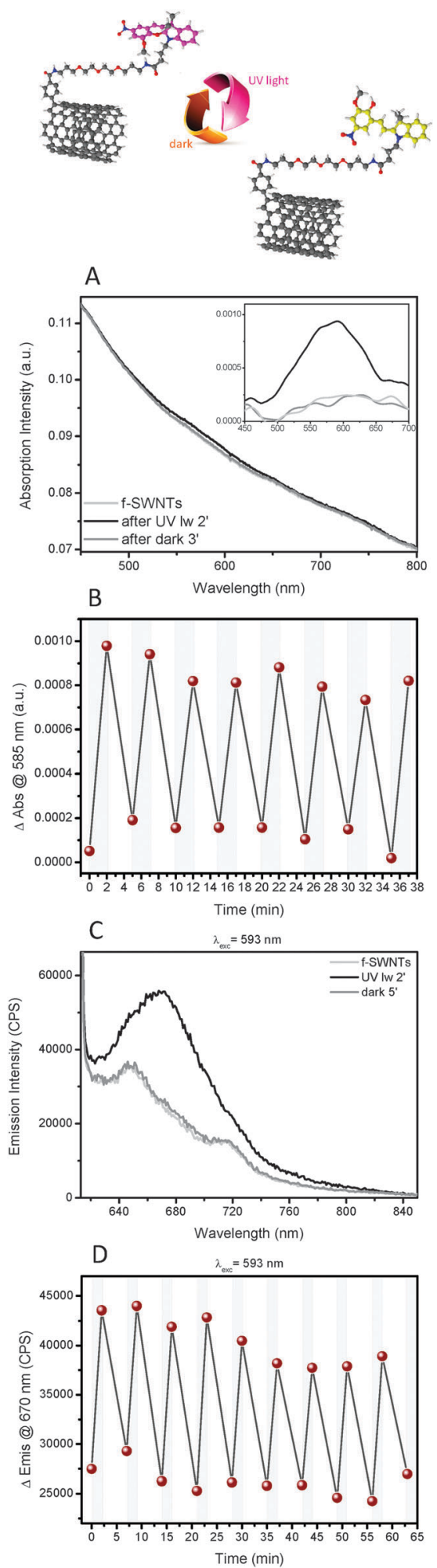

Fig. 7 On-off switching cartoon of f-SWNTs and spectroscopic studies. (A, C) f-SWNTs response to UV (365 nm) illumination for $2 \mathrm{~min}$ and dark for $3 \mathrm{~min}$. Inset: difference absorption spectra of f-SWNTs after 2 min UV, 3 min dark and additional 2 min UV illuminations. (B, D) Absorbance and emission changes at $585 \mathrm{~nm}$ and $670 \mathrm{~nm}$, respectively, of f-SWNTs solutions following UV (365 nm) and dark cycles. Gray and white bars indicate the UV and the darkness intervals respectively. The spectra were collected on the supernatant of initial $0.1 \mathrm{mg} \mathrm{mL}^{-1}$ nanotubes in DMF.

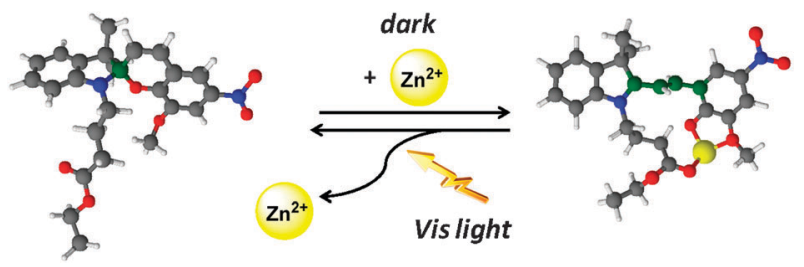

Fig. 8 Pictorial representation of the cycle of chelation and visible light modulated release of zinc by the SP-based receptor.

The successful and reproducible release of zinc metal ions by the photoactive receptor attached to SWNTs was therefore demonstrated.

Emission studies $\left(\lambda_{\mathrm{exc}}=440 \mathrm{~nm}\right)$ were additionally performed on o-SWNTs, Tour-reacted SWNTs and f-SWNTs and were compared to the emission data recorded for f-SWNTs after the addition of zinc. In the absence of metal all the nanotube solutions presented a small intensity emission band at $508 \mathrm{~nm}$ (Fig. S10 in ESI $\dagger$ ). However, this band remarkably changed both in intensity and in light responsiveness only following addition of zinc to the one functionalized with the
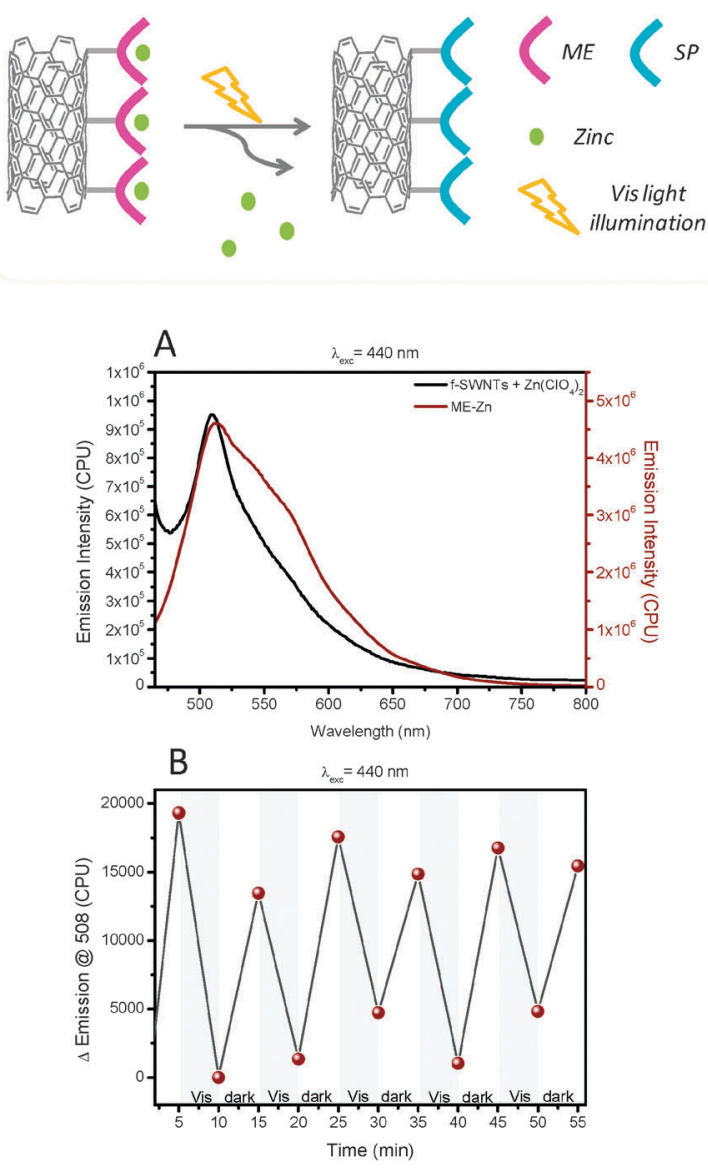

Fig. 9 Release of zinc by f-SWNTs triggered by visible light. (A) Emission spectra $\left(\lambda_{\mathrm{exc}}=440 \mathrm{~nm}\right)$ of f-SWNTs added of $\mathrm{Zn}\left(\mathrm{ClO}_{4}\right)_{2}$ $\left(10^{-1} \mathrm{M}, \mathrm{H}_{2} \mathrm{O}, 1 \mu \mathrm{L} \mathrm{mL} \mathrm{m}^{-1}\right.$ of NTs) and of the ME-Zn complex. (B) Emission changes at $508 \mathrm{~nm}$ of f-SWNTs added of $\mathrm{Zn}^{2+}$, following Vis $(3300 \mathrm{~K}$ ) illumination ( $5 \mathrm{~min}$, grey bars) and dark cycles (5 min, white bars). The spectra were collected on the supernatant of initial $0.1 \mathrm{mg} \mathrm{mL}^{-1}$ nanotubes in $\mathrm{Cl}_{2} \mathrm{Bz} / \mathrm{CH}_{3} \mathrm{CN} 9: 1$. 

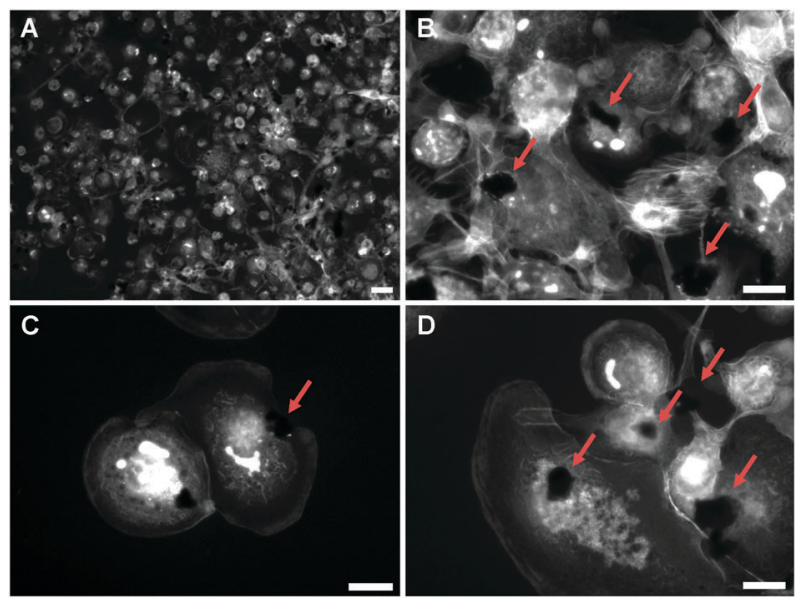

Fig. 10 Representative epifluorescent microscopy images of PMAactivated, "macrophage-like" THP-1 cells stained with the PhalloidinAlexa 546 conjugate after $24 \mathrm{~h}$ exposure to f-SWNTs. (B, D) Arrows point out f-SWNTs (3) aggregates in close contact with cells. (C) Macrophage engulfing a SWNTs aggregate (red arrow). (B-D) Intensely stained punctate foci of $\mathrm{F}$-actin are visible across the entire cell surface. The punctate F-actin fluorescence along the cell is associated with monocyte-to-macrophage differentiation induced by PMA and it is indicative of adhesive structure formation. ${ }^{48}$ Scale bar: $20 \mu \mathrm{m}$ : (A) $10 \times$, (C and D) $50 \times$ magnification.

SP receptor. This result further confirmed the successful chelation of zinc by the SP photoactive molecule anchored to the SWNT scaffold.

Epifluorescence microscopy images of PMA-activated human monocytic leukemia cells (THP-1) treated with f-SWNTs showed that "macrophage-like" cells grew in close contact with the nanotube aggregates (Fig. 10A, B and D). Careful microscopy analysis showed active engulfment of such aggregates by THP-1 cells (Fig. 10C), thus underlining the potential application of SP f-SWNTs as drug-delivery platform. Further investigations by TEM would be necessary to better clarify whether THP-1 cells are able to uptake f-SWNTs inside the cytoplasm.

\section{Conclusions}

We have demonstrated the light modulated release of antinflammatory zinc ions by a multifunctional material composed of spiropyrans and SWNTs. The exploitation of a number of complementary characterization techniques allowed the investigation of both composition and performance of chemically purified and functionalized nanotubes. The removal of toxic metal catalyst particles was confirmed by TGA and TEM, and their increased debundling and dispersibility in common solvents and water by AFM and solubility tests. The introduction of PEGylated biocompatible linkers and SP photoactive molecules was confirmed by characteristic vibrations of the functional groups in FT-IR spectra, by increased weight loss below the graphitic decomposition temperature in TGA analyses, and by the higher $I_{\mathrm{D}} / I_{\mathrm{G}}$ ratio in Raman spectra after functionalization. The introduction of a high number of organic pendants onto the tubes' surface was achieved by Tour reaction and was confirmed by a Kaiser test. UV-Vis spectroscopy has been used to demonstrate the photoswitchability of the SP receptor anchored to the SWNT scaffold and the successful and reproducible release of zinc metal ions. Based on the literature and on the preliminary results here reported, we envisage the realization of potential photo controllable SP/SWNTs based drug delivery systems (DDSs) where the nanotubes act as intracellular carriers of light modulated receptors for bioactive agents.

\section{Acknowledgements}

This work was supported by Science Foundation Ireland (PIYRA 07/YI2/I1052). The authors wish to thank the support of IRCSET and Intel (Postgraduate Research Scholarships to EDC and MD) and Trinity College Dublin (Trinity Award to EDC and $\mathrm{MN}$ ).

\section{Notes and references}

1 N. W. S. Kam, M. O'Connell, J. A. Wisdom and H. Dai, Proc. Natl. Acad. Sci. U. S. A., 2005, 102, 11600-11605.

2 D. Pantarotto, J. P. Briand, M. Prato and A. Bianco, Chem. Commun., 2004, 16-17.

3 D. Pantarotto, R. Singh, D. McCarthy, M. Erhardt, J. P. Briand, M. Prato, K. Kostarelos and A. Bianco, Angew. Chem., Int. Ed., 2004, 43, 5242-5246.

4 F. Liang and B. Chen, Curr. Med. Chem., 2010, 17, 10-24.

5 K. Kostarelos, A. Bianco and M. Prato, Nat. Nanotechnol., 2009, 4, 627-633.

6 Z. Su, S. Zhu, A. D. Donkor, C. Tzoganakis and J. F. Honek, J. Am. Chem. Soc., 2011, 113, 6874-6877.

7 A. Khazaei, M. N. Rad and M. K. Borazjani, Int. J. Nanomed., 2010, 5, 639-645.

8 M. Prato, K. Kostarelos and A. Bianco, Acc. Chem. Res., 2008, 41, 60-68.

9 N. W. S. Kam and H. J. Dai, J. Am. Chem. Soc., 2005, 127, 6021-6026.

10 J. Chen, S. Chen, X. Zhao, L. V. Kuznetsova, S. S. Wong and I. Ojima, J. Am. Chem. Soc., 2008, 130, 16778-16785.

11 V. Chaban and O. Prezhdo, ACS Nano, 2011, 5, 5647-5655.

12 Y. Ito, N. Venkatesan, N. Hirako, N. Sugioka and K. Takada, Int. J. Pharm., 2007, 337, 357-360.

13 N. Shao, J. Y. Jin, S. M. Cheung, R. H. Yang, W. H. Chan and T. Mo, Angew. Chem., Int. Ed., 2006, 45, 4944-4948.

14 N. Shao, X. Gao, H. Wang, R. Yang and W. Chan, Anal. Chim. Acta, 2009, 655, 1-7.

15 N. Shao, H. Wang, X. Gao, R. Yang and W. Chan, Anal. Chem., $2010,82,4628-4636$.

16 M. Natali, C. Aakeroy, J. Desper and S. Giordani, Dalton Trans., 2010, 39, 8269-8277.

17 M. Natali, L. Soldi and S. Giordani, Tetrahedron, 2010, 66, 7612-7617.

18 D. Movia, A. Prina-Mello, Y. Volkov and S. Giordani, Chem. Res. Toxicol., 2010, 23, 1459-1466.

19 A. S. Prasad, F. W. J. Beck, D. C. Snell and O. Kucuk, Nutr. Cancer, 2009, 61, 879-887.

20 M. M. Moore, W. Chua, K. A. Charles and S. J. Clarke, Clin. Pharmacol. Ther., 2010, 87, 504-508.

21 F. Balkwill and A. Mantovani, Clin. Pharmacol. Ther., 2010, 87, 401-406.

22 S. Rakoff-Nahoum, Yale J. Biol. Med., 2006, 79, 123-130.

23 B. Goswami, M. Rajappa, M. Sharma and A. Sharma, Int. J. Gynecol. Cancer, 2008, 18, 591-599.

24 A. Mantovani, P. Allavena, A. Sica and F. Balkwill, Nature, 2008, 454, 436-444.

25 E. Del Canto, K. Flavin, M. Natali, T. Perova and S. Giordani, Carbon, 2010, 48, 2815-2824.

26 D. S. Kohane and R. Langer, Chem. Sci., 2010, 1, 441-446.

27 H. Dumortier, S. Lacotte, G. Pastorin, R. Marega, W. Wu, D. Bonifazi, J.-P. Briand, M. Prato, S. Muller and A. Bianco, Nano Lett., 2006, 6, 1522-1528. 
28 C. M. Sayes, F. Liang, J. L. Hudson, J. Mendez, W. Guo, J. M. Beach, V. C. Moore, C. D. Doyle, J. L. West, W. E. Billups, K. D. Ausman and V. L. Colvin, Toxicol. Lett., 2006, 161, 135-142.

29 N. W. Shi Kam, T. C. Jessop, P. A. Wender and H. Dai, J. Am. Chem. Soc., 2004, 126, 6850-6851.

30 M. L. Schipper, N. Nakayama-Ratchford, C. R. Davis, N. W. S. Kam, P. Chu, Z. Liu, X. Sun, H. Dai and S. S. Gambhir, Nat. Nanotechnol., 2008, 3, 216-221.

31 A. E. Porter, M. Gass, J. S. Bendall, K. Muller, A. Goode, J. N. Skepper, P. A. Midgley and M. Welland, ACS Nano, 2009, 3, 1485-1492.

32 G. M. Mutlu, G. R. S. Budinger, A. A. Green, D. Urich, S. Soberanes, S. E. Chiarella, G. F. Alheid, D. R. McCrimmon, I. Szleifer and M. C. Hersam, Nano Lett., 2010, 10, 1664-1670.

33 K. Flavin, I. Kopf, E. Del Canto, C. Navio, C. Bittencourt and S. Giordani, J. Mater. Chem., 2011, 21, 17881-17887.

34 K. Flavin, K. Lawrence, J. Bartelmess, M. Tasior, C. Navio, C. Bittencourt, D. F. O'Shea, D. M. Guldi and S. Giordani, ACS Nano, 2011, 5, 1198-1206.

35 C. B. Aakeroy, E. P. Hurley, J. Desper, M. Natali, A. Douglawi and S. Giordani, CrystEngComm, 2010, 12, 1027-1033.
36 E. Kaiser, R. L. Colescot, C. D. Bossinge and P. I. Cook, Anal. Biochem., 1970, 34, 595-598.

37 M. Quintana and M. Prato, Chem. Commun., 2009, 6005-6007.

38 A. Rinaldi, B. Frank, D. S. Su, S. B. A. Hamid and R. Schlögl, Chem. Mater., 2011, 23, 926-928.

39 D. Movia, E. Del Canto and S. Giordani, J. Phys. Chem. C, 2010, 114, 18407-18413.

40 J. L. Bahr and J. M. Tour, J. Mater. Chem., 2002, 12, 1952-1958.

41 C. A. Dyke and J. M. Tour, Nano Lett., 2003, 3, 1215-1218.

42 B. K. Price, J. L. Hudson and J. M. Tour, J. Am. Chem. Soc., 2005, 127, 14867-14870.

43 J. L. Hudson, H. Jian, A. D. Leonard, J. J. Stephenson and J. M. Tour, Chem. Mater., 2006, 18, 2766-2770.

44 N. Nair, W. Kim, M. L. Usrey and M. S. Strano, J. Am. Chem. Soc., 2007, 129, 3946-3954.

45 L. Wei and Y. Zhang, Nanotechnology, 2007, 18, 495703.

46 C. D. Doyle, J. R. Rocha, R. B. Weisman and J. M. Tour, J. Am. Chem. Soc., 2008, 130, 6795-6800.

47 K. Sayama, K. Hara, Y. Ohga, A. Shinpou, S. Suga and H. Arakawa, New J. Chem., 2001, 25, 200-202.

48 K. M. DeFife, C. R. Jenney, E. Colton and J. M. Anderson, J. Histochem. Cytochem., 1999, 47, 65-74. 